\title{
Evaluation of psychological characteristics of Turkish children with type 1 diabetes mellitus from two demographically and geographically distinct regions
}

\author{
Rıza Taner Baran ${ }^{1,2}$, Aslı Sürer-Adanır 2,3 , Melih Nuri Karakurtt ${ }^{4}$, Münevver Dündar1,5, \\ Mülkiye Aydın ${ }^{1,5}$, Mehmet Nuri Özbek ${ }^{1,5}$, Hüseyin Demirbilek ${ }^{1,6}$ \\ ${ }^{1}$ Children's State Hospital, Clinics of Pediatric Eendocrinology, Diyarbakir; ${ }^{2}$ Antalya Training and Research Hospital, \\ Clinics of Pediatric Endocrinology, Antalya; ${ }^{3}$ Akdeniz University School of Medicine, Clinics of Child and Adolescent \\ Psychiatry, Antalya; ${ }^{4}$ Children's State Hospital, Clinics of Pediatric and Adolescent Psychiatry, Diyarbakir; ${ }^{5}$ Gazi Yasargil \\ Training and Research Hospital, Clinics of Pediatric Endocrinology, Diyarbakir; ${ }^{6}$ Hacettepe University, Faculty of Medicine, \\ Department of Pediatric Endocrinology, Ankara, Turkey. E-mail:dr_huseyin@hotmail.com
}

Received: 23rd November 2017, Revised: 9th January 2018, Accepted: 11th January 2018

SUMMARY: Baran RT, Sürer-Adanır A, Karakurt MN, Dündar M, Aydın M, Özbek MN, Demirbilek H. Evaluation of psychological characteristics of Turkish children with type 1 diabetes mellitus from two demographically and geographically distinct regions. Turk J Pediatr 2018; 60: 554-561.

Type 1 diabetes mellitus (T1DM), patients have an increased risk of psychiatric morbidity compared to their healthy counterparts. The aim of the present study is to evaluate the demographic and laboratory data and psychological characteristics of children with T1DM from two geographical regions of Turkey.

The study included 98 pediatric T1DM patients followed in pediatric endocrinology clinics from Diyarbakir $(n=50)$, an eastern city and Antalya $(n=48)$ a western city, and 43 healthy subjects from Diyarbakir $(n=20)$ and Antalya $(n=23)$. The sociodemographic data, duration of diabetes and the glycated hemoglobin levels (HbA1c) were also noted. For the evaluation of emotional and behavioral problems in children, Turkish version of The Child Behavior Checklist (CBCL) 6-18, and for depression, Child depression inventory (CDI) was used.

Patients from the Diyarbakır Diabetes Mellitus (DDM) group had a longer duration of diabetes compared to those of the Antalya Diabetes Mellitus (ADM) group, while HbAlc levels were not statistically different. Children with T1DM from Diyarbakır reported higher problem scores in CBCL in majority of domains and both internalizing and externalizing subscores compared to the controls and in all domains compared to the patients from Antalya. The CDI scores of the DDM group were also significantly higher than those of the ADM group.

In conclusion, diabetic children from Diyarbakır had more problems in emotional, social and behavioral domains compared to the healthy peers and patients from Antalya, indicating that T1DM brought more psychosocial burden to these patients independently from the metabolic control. Pediatric specialists working in the eastern region should be more precautious with diabetic patients in terms of comorbid psychiatric conditions and psychiatric referral when needed.

Key words: type 1 diabetes mellitus, children, disease burden, depression, child behavior checklist.

Type 1 diabetes mellitus (T1DM), one of the most common chronic diseases in childhood, has an increasing trend worldwide, particularly in children under the age of 15 years. ${ }^{1-3}$
Although it varies according to geographical regions and populations, the overall annual increase in incidence rate is estimated to be around $3 \% .^{2}$ 
Although, insulin therapy given in various regimen is the mainstay of the treatment in T1DM, a requirement of dietary intervention, self blood glucose monitoring, lifestyle modification and physical exercise bring a burden for the families and their diabetic children. ${ }^{4,5}$ Despite the presence of a "National Diabetes Education Program in School" which has improved the conditions, parents still hesitate due to difficulties in diabetes management during the school period as limitations in accessing a convenient place to store their insulin, measuring their blood glucose, arranging appropriate diet and calculating and administering their insulin doses and lack of health practitioners or staff educated to help diabetic children who may require their assisstance in case of symptomatic hypoglycemia continues to be a problem. In addition, children usually have concerns about coping with the burden of their diabetes which may result in discrimination, stigmatization and limited social relationships. Therefore, T1DM patients have an increased risk of psychiatric morbidity compared to their healthy counterparts. ${ }^{6}$ Depression is one of the most common psychiatric disorders in children and adolescents with $\mathrm{T}_{1} \mathrm{DM}^{7}$. These behavioral/ mental health challenges are associated with poor compliance to treatment, thereby leading to poor glycemic control and related to serious short- and long-term complications. 8,9

Although, the psychosocial aspects of T1DM have been relatively well studied, there is a lack of large scale multicenter populationbased studies focused on the differences among different regions of the same country. Additionally, in Turkey, studies focused on the burden of diabetes on children and their families are scarce.

Turkey has seven geographical regions which largely differ in terms of their socio-demographic structures, educational levels, employment rates, level of welfare, infrastructure, and economic structure. ${ }^{10}$ There is a huge EastWest discrepancy in the development of working and earning conditions, agriculture and industry, in the direction of migration flows and in the potential for public or private investment. ${ }^{11}$ The Burden of Disease Study in 2005 has shown that the Middle, West, North and South regions had similar patterns with developed European countries while the East showed disease and mortality patterns similar to developing countries. ${ }^{12}$

In the present study, we investigate factors related to the mental health of diabetic children and evaluate the possible regional differences. In order to explore the possible impacts of the regional heterogeneity of Turkey on mental health of diabetic children, we recruited T1DM children who were followed at diabetes clinics from two geographical regions of Turkey.

\section{Material and Methods}

\section{Participants}

Our study included 98 pediatric T1DM patients followed in our pediatric endocrinology clinics from Diyarbakir (DDMgroup, $\mathrm{n}=50$ ), an eastern city and Antalya (ADM group, $n=48$ ) a western city, and 43 healthy subjects from Diyarbakir (DC, $n=20$ ) and Antalya (AC, $n=23)$. Children who themselves or their family rejected to sign an informed consent, those participants with lacking data about their family, those with a mental delay, noncompliance to the questionnaire, and those having a psychiatric disorder were excluded. Trained physicians interviewed all patients and the families according to a standardized protocol. Monthly family income, education and health status of mother and father, and number of siblings were questioned. Data for diabetic patients' characteristics such as current age, gender, age at diagnosis of T1DM, duration of diabetes (years), and the glycated hemoglobin level (HbA1c) levels were extracted from their hospital files. The study was approved by institutional review board of Gazi Yasargil Training and Research Hospital (Date/report number of approval: 05.06.2017/59) and performed according to the Helsinki declaration. A written informed consent was obtained from all patients/their legal guardians.

\section{Measurements}

For the evaluation of emotional and behavioral problems in children, Turkish version of The Child Behavior Checklist (CBCL) 6-18 was used. ${ }^{14} \mathrm{CBCL}$ is a parent-report questionnaire developed by Thomas M. Achenbach, on which the child is rated on various behavioral and emotional problems. ${ }^{15}$ It is one of the most widely-used standardized methods for 
evaluating maladaptive behavioral and emotional problems in subjects between the ages of 6 and 18. Items are rated on a three-point scale $(0=$ not true; $1=$ somewhat or sometimes true; 2 =very true/often true) and consists of eight subscales. It assesses internalizing (i.e., depressive, anxious, and overcontrolled) and externalizing (i.e., hyperactive, noncompliant, aggressive, and undercontrolled) behaviors. Several subareas are measured including anxiety/depression, social withdrawal, somatic problems, social problems, thought problems, attention problems, delinquent behavior and aggressive behavior. Higher scores indicate greater pathology.

In children, depression was rated using The Children's Depression Inventory (CDI). This self-report 27-item scale was developed by Kovacs $^{16}$ and its reliability and validity in Turkish language was developed by $\mathrm{Oy}^{17}$. The CDI has established good reliability and validity for describing depressive symptoms and is one of the most widely used instruments for assessing the presence and severity of depressive symptoms in children between the ages $7-17^{18}$. It is a 3-point likert scale, in order of increasing severity from 0 to 2 . The one that characterized their symptoms best during the past 2 weeks was chosen by the children. The sum of item scores gives a total depression score, which ranges from 0 to 54 . A higher CDI score means a higher depressive state.

Since diabetic patients were from two cities that are distinct in terms of their socio-demographic structures and life standards which may have effects on the test scores, data obtained from T1DM patients were compared to those of age and sex matched healthy subjects from both cities.

To evaluate the relationship between psychological status of patients and its relationship with metabolic control of their diabetes, we assessed the HbA1c levels and duration for diabetes onset.

\section{Statistical analysis}

Statistical analysis was carried out using IBM SPSS Statistics for Windows (Version 22.0. Armonk, NY: IBM Corp. Released 2013). Data were expressed as mean \pm SD (range) or median ( $25^{\text {th }}-75^{\text {th }}$ interquartile range). Shapiro-Wilk test was used to test for a normality distribution of the data. $\chi^{2}$-test (or Fisher's exact test) was performed for comparison of the ratios. Means were compared using Student's t test and ANOVA for normally distributed data, while for non-normally distributed data medians were compared using non-parametric Kruskal Wallis and Mann-Whitney U tests. Spearman-Rank test was performed for correlations. A p value $<0.05$ was considered statistically significant.

\section{Results}

\section{Clinical and family characteristics of diabetic patients and controls}

The study included 98 pediatric TIDM patients and 43 healthy controls. There was no statistically significant difference between the age of patients and parents from the 4 groups. Patients from the DDM group had a

Table I. Sociodemographic and Clinical Characteristics of T1DM Patients and Controls.

\begin{tabular}{lccccc}
\hline & $\begin{array}{c}\mathrm{DDM} \\
(\mathrm{n}=50)\end{array}$ & $\begin{array}{c}\text { ADM } \\
(\mathrm{n}=48)\end{array}$ & $\begin{array}{c}\mathrm{DBC} \\
(\mathrm{n}=20)\end{array}$ & $\begin{array}{c}\text { AC } \\
(23)\end{array}$ & $\begin{array}{c}\mathrm{P} \\
\text { value }\end{array}$ \\
\hline Age (year) & $12.1 \pm 3.4$ & $11.5 \pm 2.8$ & $12.2 \pm 4.4$ & $12.6 \pm 2.7$ & 0.589 \\
Gender (F/M) & $32 / 18$ & $26 / 22$ & $10 / 10$ & $12 / 11$ & 0.622 \\
Diabetes duration (year) & $6.2 \pm 2.5$ & $2.9 \pm 1.2$ & - & - & 0.000 \\
HbA1c(\%) & $10.4 \pm 2.9$ & $9.5 \pm 2.6$ & - & - & 0.115 \\
Maternal age & $37.7 \pm 6.6$ & $38.2 \pm 5.3$ & $37.4 \pm 5.6$ & $39.7 \pm 6.0$ & 0.496 \\
Paternal age & $42.7 \pm 7.6$ & $41.1 \pm 5.4$ & $40.9 \pm 5.8$ & $42.5 \pm 5.8$ & 0.618 \\
Number of siblings & $\mathrm{NA}$ & 1 & 2 & 2 & 0.569 \\
Income (TL/month) & $\mathrm{NA}^{*}$ & $2200 \pm 750$ & $2250 \pm 786$ & $1913 \pm 668$ & 0.234 \\
\hline
\end{tabular}

*NA: Not available. The data of family income for the DDM group was lacking and unreliable. These families usually do not have a regular income and receieve financial support from government for their ill child thereby avoid giving correct information about their family income. 
Table II. Comparison of CBCL and CDI Test Scores for T1DM Patients and Controls*

\begin{tabular}{|c|c|c|c|c|}
\hline & & T1DM patients & Control & $\mathrm{P}$ \\
\hline \multirow{4}{*}{$\begin{array}{l}\text { Children's Depression } \\
\text { Inventory score }\end{array}$} & Diyarbakır & $10.0(6.5-12.5)$ & $7.0(4.0-12.5)$ & 0.133 \\
\hline & Antalya & $6.0(4.0-8.0)$ & $9.0(7.0-11.0)$ & 0.018 \\
\hline & $p$ & $<0.001$ & 0.305 & \\
\hline & Total & $8.0(5.0-12.0)$ & $9.0(5.0-12.0)$ & 0.965 \\
\hline \multirow[t]{4}{*}{ Anxiety/ depression } & Diyarbakır & $0.46(0.31-0.85)$ & $0.38(0.12-0.46)$ & 0.029 \\
\hline & Antalya & $0.15(0.08-0.31)$ & $0.38(0.15-0.62)$ & 0.076 \\
\hline & $p$ & $<0.001$ & 0.778 & \\
\hline & Total & $0.38(0.15-0.73)$ & $0.38(0.15-0.53)$ & 0.582 \\
\hline \multirow[t]{4}{*}{ Anxiety/ withdrawal } & Diyarbakır & $0.37(0.13-0.63)$ & $0.25(0.00-0.50)$ & 0.200 \\
\hline & Antalya & $0.13(0.00-0.38)$ & $0.25(0.13-0.50)$ & 0.071 \\
\hline & $p$ & 0.009 & 0.420 & \\
\hline & Total & $0.25(0.06-0.50)$ & $0.25(0.00-0.50)$ & 0.848 \\
\hline \multirow[t]{4}{*}{ Somatic problems } & Diyarbakır & $0.36(0.18-0.68)$ & $0.09-(0.00-0.45)$ & 0.004 \\
\hline & Antalya & $0.00(0.00-0.18)$ & $0.09(0.18-0.45)$ & 0.314 \\
\hline & $p$ & $<0.001$ & 0.770 & \\
\hline & Total & $0.18(0.00-0.45)$ & $0.09(0.00-0.45)$ & 0.083 \\
\hline \multirow[t]{4}{*}{ Social problems } & Diyarbakır & $0.50(0.27-0.68)$ & $0.27(0.14-0.45)$ & 0.033 \\
\hline & Antalya & $0.09(0.00-0.27)$ & $0.18(0.09-0.68)$ & 0.058 \\
\hline & $p$ & $<0.001$ & 0.657 & \\
\hline & Total & $0.27(0.09-0.59)$ & $0.27(0.09-0.45)$ & 0.837 \\
\hline \multirow[t]{4}{*}{ Thought problems } & Diyarbakır & $0.21(0.11-0.36)$ & $0.7(0.07-0.25)$ & 0.033 \\
\hline & Antalya & $0.07(0.00-0.21)$ & $0.14(0.07-0.25)$ & 0.341 \\
\hline & $p$ & 0.009 & 0.503 & \\
\hline & Total & $0.21(0.07-0.28)$ & $0.14(0.07-0.28)$ & 0.298 \\
\hline \multirow[t]{4}{*}{ Attention problems } & Diyarbakır & $0.50(0.30-0.80)$ & $0.40(0.20-0.60)$ & 0.190 \\
\hline & Antalya & $0.10(0.00-0.60)$ & $0.40(0.05-0.80)$ & 0.201 \\
\hline & $p$ & 0.001 & 0.922 & \\
\hline & Total & $4.00(0.10-0.70)$ & $4.00(0.20-0.70)$ & 0.969 \\
\hline \multirow[t]{4}{*}{ Delinquent behavior } & Diyarbakır & $0.24(0.12-0.29)$ & $0.18(0.12-0.26)$ & 0.260 \\
\hline & Antalya & $0.12(0.06-0.18)$ & $0.18(0.06-0.24)$ & 0.343 \\
\hline & $p$ & 0.001 & 0.467 & \\
\hline & Total & $0.18(0.06-0.29)$ & $0.18(0.12-0.24)$ & 0.698 \\
\hline \multirow[t]{4}{*}{ Aggressive behavior } & Diyarbakır & $0.44(0.28-0.75)$ & $0.28(0.08-0.39)$ & 0.010 \\
\hline & Antalya & $0.11(0.00-0.28)$ & $0.28(0.06-0.50)$ & 0.209 \\
\hline & $p$ & $<0.001$ & 0.903 & \\
\hline & Total & $0.28(0.11-0.67)$ & $0.28(0.06-0.44)$ & 0.258 \\
\hline \multirow{4}{*}{$\begin{array}{l}\text { Internalizing } \\
\text { subscores }\end{array}$} & Diyarbakır & $0.40(0.28-0.63)$ & $0.23(0.13-0.47)$ & 0.012 \\
\hline & Antalya & $0.13(0.04-0.28)$ & $0.26(0.13-0.55)$ & 0.055 \\
\hline & $p$ & $<0.001$ & 0.643 & \\
\hline & Total & $0.31(0.13-0.48)$ & $0.24(0.13-0.49)$ & 0.408 \\
\hline \multirow{4}{*}{$\begin{array}{l}\text { Externalizing } \\
\text { subscores }\end{array}$} & Diyarbakır & $0.33(0.21-0.55)$ & $0.24(0.14-0.33)$ & 0.028 \\
\hline & Antalya & $0.14(0.03-0.13)$ & $0.23(0.06-0.37)$ & 0.258 \\
\hline & $p$ & $<0.001$ & 0.761 & \\
\hline & Total & $0.23(0.11-0.45)$ & $0.23(0.09-0.34)$ & 0.371 \\
\hline
\end{tabular}

*Data are presented as median $\left(25^{\text {th }}-75^{\text {th }}\right.$ interquartile range). 


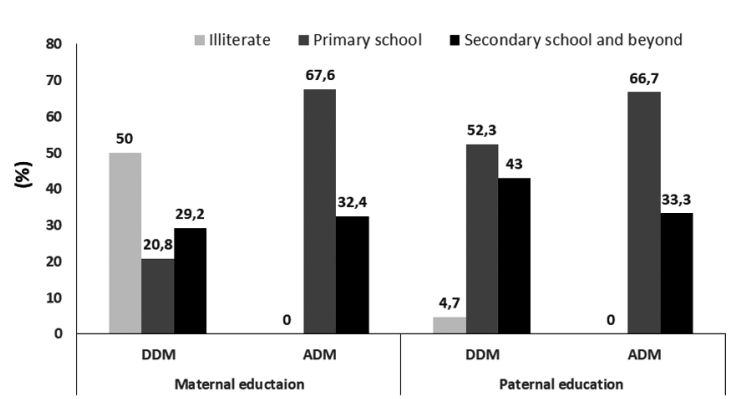

Fig. 1. Parental educational status of T1DM patients from Diyarbakır and Antalya.

longer duration of the diabetes compared to those of the ADM group, while, HbA1c levels were not statistically different (Table I).

Evaluation of parental education status revealed a lower maternal educational status in DDM group compared to ADM group $(\mathrm{p}<0.001)$, while the education status of fathers was not statistically different $(\mathrm{p}=0.314)$ (Fig. 1). Although all children recruited were at schoolage, 10 out of $33(30 \%)$ of children from the DDM group did not go to school, while only one of 34 children from ADM group did not go to school $(\mathrm{p}=0.003)$.

\section{$C B C L$ and $C D I$ scores of the groups}

DDM vs. DC group: Compared to DC, children from DDM group had higher problem scores in CBCL in all subscores except for anxiety/ depression, attention problem, and delinquent behavior subscores and CDI test scores did not reach a statistically significant difference (Table II).

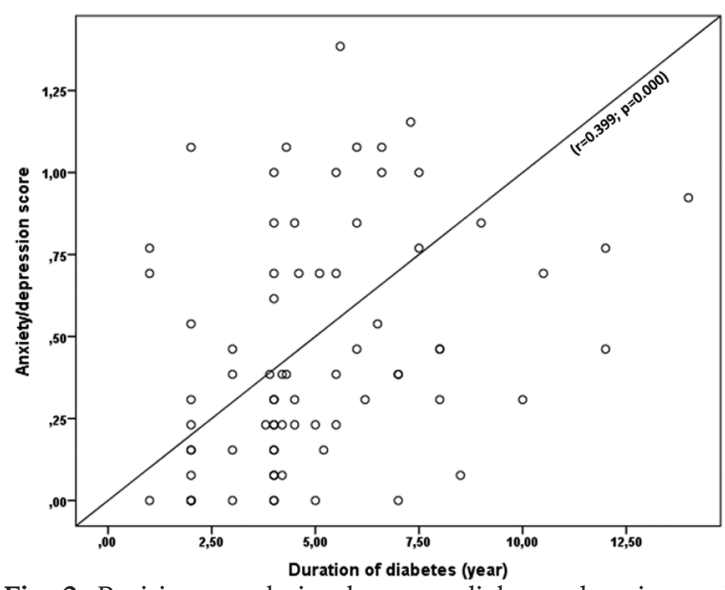

Fig. 2. Positive correlation between diabetes duration and depressive behavior score.

$D D M$ vs. ADM group: Patients from Diyarbakir had statisctically significant higher problem scores both in CDI and in all subscores of CBCL (Table II).

ADM group vs. AC: T1DM children from Antalya had better scores compared to controls in CDI while there was no statistically significant difference in any of the CBCL subscores (Table II).

Diabetes vs. Controls: Evaluation of the overall scores for T1DM patients and controls recruited from both cities revealed no statistically significant difference neither in CDI scores nor CBCL subscores (Table II).

In correlation analysis, duration of the diabetes was found to have a negative impact on test scores, while, HbA1c has not correlation with any test parameters (Fig. 2 and Table III).

Table III. Correlation Analysis of the Test Scores with HbAlc and Duration of Diabetes

\begin{tabular}{lcccccc}
\hline & \multicolumn{2}{c}{ HbA1c } & & \multicolumn{2}{c}{ Duration of diabetes } \\
\cline { 2 - 3 } \cline { 6 - 7 } & $\mathrm{r}$ & $\mathrm{p}$ & & $\mathrm{r}$ & $\mathrm{p}$ \\
\hline Children's Depression Inventory score & 0.047 & & 0.670 & & 0.319 & 0.002 \\
Anxiety/ depression score & 0.120 & & 0.318 & & 0.399 & 0.000 \\
Anxiety/ withdrawal score & 0.044 & & 0.712 & & 0.215 & 0.063 \\
Somatic problems score & 0.203 & & 0.086 & & 0.457 & 0.000 \\
Social problems score & 0.100 & & 0.398 & & 0.457 & 0.000 \\
Thought problems score & 0.119 & & 0.395 & & 0.168 & 0.148 \\
Attention problems score & 0.179 & & 0.131 & & 0.348 & 0.001 \\
Delinquent behavior score & 0.139 & 0.240 & & 0.426 & 0.000 \\
Aggressive behavior score & 0.153 & 0.197 & & 0.441 & 0.000 \\
Internalizing subscores & 0.167 & 0.164 & & 0.420 & 0.000 \\
Externalizing subscores & 0.152 & & 0.198 & & 0.453 & 0.000 \\
\hline
\end{tabular}




\section{Discussion}

The present study evaluated the psychological characteristics of pediatric T1DM patients from two distinct regions of Turkey. The two major findings of the study were the positive correlation between the duration of the disease and psychosocial burden of the diabetes on patients; and the difference between the 2 geographical regions in terms of depression and other emotional and behavioral problems.

The presence of a relationship between duration of T1DM and psychopathology have been reported in previous studies. Kovacs et $\mathrm{al}^{7}$. reported an association between the duration of disease and major psychiatric disorders and non-depressive disorders (but not depressive disorders). In another study, CDI and CBCL total behavior problem scores were reported higher in the patients with a disease duration of longer than 1 year. ${ }^{19}$ These findings suggest that longer duration of T1DM maybe associated with increase in the disease burden thereby leading to an increased risk of psychological problems. Similarly, in the present study a possible explanation for the higher scores on CBCL and CDI in DDM group is the longer duration of diabetes in patients recruited from this region.

Regarding the relationship between psychiatric problems and metabolic control, previous studies had controversial results. While some studies have found a positive relationship, some others have not. ${ }^{20-23}$ In our study, we did not find a statistically significant association between the HbA1c level and psychopathology, either. Presence of such controversies suggest that the psychological burden of the disease may vary according to the individual and familial factors along with demographic and socio-economic structures of the populations.

An association between T1DM and several psychiatric disorders have also been reported. The mostly emphasized disorders are anxiety, mood disorders like depression and behavioral disorders $5,23-25$. In the present study, compared to the control subjects and T1DM patients from Antalya, T1DM patients from Diyarbakır had higher problem scores in CBCL. Namely, children with T1DM from Diyarbakır have higher problem scores both in emotional and behavioral domains (anxiety/ depression, aggressive behavior, delinquent behavior) and social domain (social competence, social problems). Additionally, their CDI scores were also significantly higher than those of T1DM patients from Antalya. These results suggested that children with T1DM from Diyarbakır had more psychosocial burden and depressive state compared to the healthy children and patients from Antalya. However, no significant difference was found between the healthy children and patients from Antalya in terms of psychopathology. Moreover, patients with T1DM from Antalya even had slightly better CDI scores than their counterpart controls living in Antalya. These controversial results were attributed to the shorter duration of diabetes suggesting either little cumulative burden or avoidance of children at the acute stage to explore their feeling, or further efforts of parents from Antalya for the well being of their children with diabetes.

The burden of diabetes is closely related to socioeconomic and cultural status, education level, and religious belief. We could not compare the family income of the families of T1DM patients from the 2 cities, as the Diyarbakır data was found unreliable (As the families usually have not a regular and constant income, take extra financial support from government, beyond health expenses, for their ill child thereby avoid giving information about their family income). However, according to Socioeconomic developmental survey of provinces and regions (SEGE 2011) report, Antalya is fifth on the list, whereas Diyarbakır is sixtyseventh $^{26}$. In addition, as a general perception the family income and socioeconomic status are lower in the east region of Turkey, including Diyarbakır, compared to Antalya, the major tourist city in the west region. We, therefore, thought that higher problem scores might be realated to the lower socieconomic status of families from Diyarbakır. Nevertheless, lack of statistically significant difference between the metabolic control of patients and coverage of all health expenses of all children under 18 year-old by the social security institute in Turkey seems to be a contradiction. Lack of difference in metabolic control can be attributed to shorther duration of diabetes in ADM group which may included recently diagnosed patients with higher HbA1c levels.

On the other hand, having lower maternal 
educational status in DDM group perhaps negatively affected their diabetes education and involvement to the management of the diabetes and need for self-management thereby increased the burden of the disease for diabetic children from Diyarbakır. Additionally, leaving school, thereby lacking the natural social enviroment providing relationships with their peers in about one of three children from Diyarbakır may have contributed to the higher problem scores as well as depressive state in this group of patients. Therefore, lower socioeconomic status may still effect the quality of education of both children and parents, accessibility of mental health services and psychosocial support, possibly placing more psychosocial burden on the children with T1DM from Diyarbakır.

The strengths of the present study are the use of validated and highly standardized self-report measures of depression and psychopathology in 2 samples of patients with T1DM from 2 regions of Turkey and comparing them with a control group. Nonetheless, there are some limitations worthy of note. First, this study was cross-sectional and examined a relatively small sample that may not be representative of the examined population. Second, we included only 2 regions, instead of all 7 of them, and finally, the probable existence of additional factors not yet evaluated that could be a determinant in the psychosocial burden of patients with T1DM and contribute to these regional disparities. Future research is needed in in this respect.

In conclusion, in the present study diabetic children from Diyarbakır were found to have more problems both in emotional, social and behavioral domains compared to healthy peers and patients from Antalya, indicating that T1DM brought more psychosocial burden independently from the metabolic control. Pediatric specialists especially who are working in the eastern region should be more precautious with diabetic patients in terms of comorbid psychiatric conditions and make psychiatric referral when needed. Socioeconomic improvement initiatives by the government are also required.

\section{REFERENCES}

1. Gale EA. Type 1 diabetes in the young: The harvest of sorrow goes on. Diabetologia 2005; 48: 1435-1438.

2. Patterson CC, Dahlquist GG, Gyürüs E, Green A, Soltész G; EURODIAB Study Group. Incidence trends for childhood type 1 diabetes in Europe during 1989. 2003 and predicted new cases 2005-20: A multicentre prospective registration study. Lancet 2009; 373: 2027 2033.

3. International Diabetes Federation. IDF Diabetes Atlas, (7th ed). Brussels, Belgium: International Diabetes Federation, 2015. Available at https://www.idf.org/elibrary/epidemiology-research/diabetes-atlas.html (Accessed 22.05.2017)

4. Soni $\mathrm{A}, \mathrm{Ng} \mathrm{SM}$. Intensive diabetes management and goal setting are key aspects of improving metabolic control in children and young people with type 1 diabetes mellitus. World J Diabetes 2014; 5: 877-881.

5. Dantzer C, Swendsen J, Maurice-Tison S, Salamon R. Anxiety and depression in juvenile diabetes: A critical review. Clin Psychol Rev 2003, 23: 787-800.

6. Lustman PJ, Clouse RE. Depression in diabetic patients: The relationship between mood and glycemic control. J Diabetes Complications 2005; 19: 113-122.

7. Kovacs M, Mukerji P, Iyengar S, Drash A. Psychiatric disorder and metabolic control among youths with IDDM. A longitudinal study. Diabetes Care 1996; 19: 318-323.

8. Goldston DB, Kelley AE, Reboussin DM, et al. Suicidal ideation and behavior and noncompliance with the medical regimen among diabetic adolescents. J Am Acad Child Adolesc Psychiatry 1997; 36: 1528-1536.

9. Helgeson VS, Siminerio L, Escobar O, Becker D. Predictors of metabolic control among adolescents with diabetes: A 4-year longitudinal study. J Pediatr Psychol 2009; 34: 254-270.

10. Ozaslan M, Dinçer B, Özgür H. Regional Disparities and Territorial Indicators in Turkey: Socio-Economic Development Index (SEDI) Enlargement, Southern Europe, and the Mediterranean, Volos, Greece: The department of planning and regional development University of Thessaly and the Greek section of ERSA, Paper presented at: 46th Congress of the European Regional Science Association (ERSA); 2006.

11. Celebioglu F, Dall'erba S. Spatial disparities across the regions of Turkey: An exploratory spatial data analysis. Ann Reg Sci 2010; 45: 379-400.

12. Baskent University/Ministry of Health/Refik Saydam Hygiene Center Presidency, School of Public Health (2004) National Burden of Disease and Cost Effectiveness Project-Final Report, 1st ed.

13. (Available at http://ekutuphane.sagem.gov.tr/kitaplar/ turkey_burden_of_disease_study.pdf, Accessed 22.05.2017)

14. Satman İlhan, and TURDEP-II Çalışma Grubu. "TURDEP-II Sonuçları." Türk Endokronoloji ve Metabolizma Derneği [homepage on the Internet]. (Available at http://www. turkendokrin. org/fi les/fi le/TURDEP_II_2011. Accessed 23.05.2017) 
15. Erol N, Akcakın M, Aslan L. Cocuk Davranısssal Değerlendirme Olceği'nin Uyarlanması ve standardizasyon calışması. V. Ulusal Cocuk ve Ergen Psikiyatri Kongresi. 30 Nisan-3 Mayıs, A. U. Tip Fakultesi. Cocuk Psikiyatrisi, Ankara 1995, in Turkish.

16. Achenbach TM. Manual for the Child Behavior Checklist 14-18 and 1991 Profile. VT. Burlington: University of Vermont Department of Psychiatry 1991.

17. Kovacs M. The Children's Depression Inventory (CDI). Psychopharmacol Bull 1985; 21: 995-998.

18. Oy B. Çocuklar için depresyon ölçeği: Geçerlilik ve güvenirlik çalışması. Türk Psikiyatri Dergisi 1991; 2: 132-136.

19. Smucker MR, Craighead WE, Craighead LW, Green BJ. Normative and reliability data for the Children's Depression Inventory. J Abnorm Child Psychol 1986; 14: 25-39.

20. Cho E, Shin SH, Eun SH, et al. Psychological characteristics of Korean children and adolescents with type 1 diabetes mellitus. Ann Pediatr Endocrinol Metab 2013; 18: 122-127.

21. Johnson B, Eiser C, Young V, Brierley S, Heller S. Prevalence of depression among young people with type 1 diabetes: A systematic review. Diabet Med 2013; 30: 199-208.
22. Korbel CD, Wiebe DJ, Berg CA, Palmer DL. Gender differences in adherence to type 1 diabetes management across adolescence: The mediating role of depression. Children's Health Care 2007; 36: 83-98.

23. Akbas S, Karabekiroğlu K, Ozgen T, et al. Association between emotional and behavioral problems and metabolic control in children and adolescents with Type 1 diabetes. J Endocrinol Invest 2009; 32: 325-329.

24. Northam EA, Matthews LK, Anderson PJ, Cameron FJ, Werther GA. Psychiatric morbidity and health outcome in Type 1 diabetes: Perspectives from a prospective longitudinal study. Diabet Med 2005; 22: 152-157.

25. Kovacs M, Goldston D, Obrosky DS, Bonar LK. Psychiatric disorders in youths with IDDM: Rates and risk factors. Diabetes Care 1997; 20: 36-44.

26. Grey M, Whittemore R, Tamborlane W. Depression in type 1 diabetes in children: Natural history and correlates. J Psychosom Res 2002; 53: 907-911.

27. Socio-economic developmental survey of provinces and regions (SEGE 2011) (Available at http://www. kalkinma.gov.tr/Lists/Yaynlar/Attachments/548/SEGE2011.pdf, Accessed 22.05.2017) 